\title{
POTENTIAL HOLISTIC PREVENTIVE AND THERAPEUTIC EFFECTS OF GARCINIA MANGOSTANA EXTRACT OR ISOLATES IN TYPE 2 DIABETES MELLITUS: A REVIEW
}

\section{JOANNA ERIN HANRAHAN', PRISCILLA AYA MAHESWARI SUBROT0', RAHARDI PRASETIA PRIAWAN', DESAK GEDE BUDI KRISNAMURTI2*}

1Undergraduate student, Faculty of Medicine, Universitas Indonesia, 2Department of Medical Pharmacy, Faculty of Medicine, Universitas Indonesia

Email: desak.gede@ui.ac.id

Received: 13 Dec 2018, Revised and Accepted: 10 Mar 2019

\section{ABSTRACT}

Objective: The need for long-term medication in diabetes mellitus has led to a search for herbal medicines as alternative treatments. Several studies have shown that extract or isolates of Garcinia mangostana can help prevent and treat type 2 diabetes mellitus (T2DM).

Methods: This review was conducted by searching various databases, including PubMed, ClinicalKey, ScienceDirect, and EBSCOhost. We analyzed papers published within the previous $10 \mathrm{y}$.

Results: All in vitro, in vivo, and clinical studies that evaluated the pharmacological effects of extract or isolates of G. mangostana in T2DM were reviewed. G. mangostana was found to suppress adipogenesis and regulate lipid homeostasis, thus improving lipid profiles and preventing T2DM. G. mangostana also demonstrated hypoglycemic properties, including the ability to decrease fasting blood glucose and mildly increase pancreatic $\beta$ cell numbers and activity. The mangosteen-treated group in one study showed a decrease in Homeostatic Model Assesment for Insulin Resistance (HOMA-IR), indicating improved insulin sensitivity, along with a significant decrease in the high-sensitivity CRP (hs-CRP) levels. Histopathology showed that the $\alpha$-mangostin-treated group had less damage to pancreatic $\beta$ cells, healthier hepatocytes and central veins, and less glomerular and tubular epithelial necrosis than the diabetic control group. Moreover, the antioxidant effect of $G$. mangostana was shown to protect against the micro-and macrovascular damage caused by T2DM.

Conclusion: Extract or isolates of G. mangostana possess strong potential to prevent and treat T2DM. Further research evaluating long-term outcome biomarkers in humans is needed to confirm the drug's glycemic control capacity.

Keywords: Garcinia mangostana, Mangosteen, $\alpha$-mangostin, Type 2 diabetes mellitus

(C) 2019 The Authors. Published by Innovare Academic Sciences Pvt Ltd. This is an open access article under the CC BY license (http://creativecommons. org/licenses/by/4. 0/) DOI: http://dx.doi.org/10.22159/ijap.2019.v11s6.33525

\section{INTRODUCTION}

Diabetes mellitus (DM) is a hyperglycemic condition caused by metabolic disorders. The prevalence of DM has drastically increased from 30 million cases in 1985 to 224 million cases in 2014; this number is predicted to double in the next $30 \mathrm{y}$. In 2015, 1.6 million deaths were caused by diabetes [1]. The increase in cases of DM is due to our modern lifestyle that leads to obesity and less physical activity [2].

Type-2 DM is a chronic disease that requires long-term medication, with the associated side effects and costs. First-line medication for type-2 DM after lifestyle modification is metformin, followed by sulfonylurea. Metformin has gastrointestinal side effects whereas sulfonylurea causes weight gain and hypoglycemia [3]. Other side effects that may occur include headache, dizziness, nausea, and hypersensitivity reactions [4].

For these reasons, herbal medication has become an alternative treatment for DM, with fewer side effects and lower cost. Herbs that have shown effects in clinical trials of DM treatment include Gymnema sylvestre, Momordica charantia, Folium mori, Trigonella foenumgraecum, Rhizoma coptidis, Ginkgo biloba, Radix ginseng, and Garcinia mangostana. Pharmacological mechanisms of these herbs include increasing glycogen production, stimulating insulin secretion, increasing glucose uptake in the peripheral tissues, increasing insulin sensitivity, and decreasing carbohydrate absorption [5].

Prevention of type-2 DM is as important as treatment and is significantly less expensive. Herbs that have been shown to have preventive effects in type-2 DM include capsaicin, chili pepper, Curcuma longa, Chinese tea, and genistein from soybeans [6].

Garcinia mangostana is a tropical fruit commonly found in Southeast Asia. G. mangostana has been popularly used to treat inflammation, skin infections, and diarrhea [7]. More than 68 xanthones have been identified in all parts of mangosteen. One study identified the chemical constituents in a dichloromethane extract of mangosteen seed and pulp [8]. The seed contained triacylglycerol and stigmasterol, while the pulp contained $\alpha$-mangostin, 3 -isomangostin, $\delta$-tocotrienol, and vitamin E. Fifty of the 68 xanthones identified in mangosteen are contained in the pericarp (fruit hull). The major constituent in the pericarp is $\alpha$-mangostin. Other constituents include isomangostin, mangotinone, 8-deoxygartanin, gartanin, and $\beta$-mangostin. Among these constituents, $\alpha$-mangostin has been most widely studied and has shown antioxidant, anticarcinogen, antibacterial, and anti-inflammatory effects, as well as apoptosis induction potential [9]. Studies have also shown that G. mangostana extract can help prevent and treat type-2 DM. The aim of this review was to summarize the effectiveness of extracts or isolates of $G$. mangostana in the prevention and treatment of type-2 DM.

\section{MATERIALS AND METHODS}

We conducted a literature search of various databases, including PubMed, ClinicalKey, ScienceDirect, and EBSCOhost, with keywords "Garcinia mangostana," "mangosteen," "mangostin," AND "insulin," "diabetes," "blood glucose," "hyperglycemic." We analyzed papers published within the previous $10 \mathrm{y}$.

\section{RESULTS AND DISCUSSION}

The pathophysiology of type-2 DM includes a series of conditions that lead to hyperglycemia. Obesity often leads to type-2 DM. In patients with obesity, the amount of adiponectin, which helps to enhance insulin sensitivity, decreases. Increased production of adipokines and increased adipocyte numbers in obesity cause inflammation, which elevates IL-6 and C-reactive protein (CRP). The decrease in insulin sensitivity triggers the production of more insulin, thus creating hyperinsulinemia. At some point, pancreatic islet cells cannot maintain homeostasis, resulting in hyperglycemia [2]. 
Insulin resistance also induces a decline in glucose utilization by tissues, thus creating the perception of glucose shortage in the body. This in turn triggers the liver to increase gluconeogenesis and results in fasting hyperglycemia and decreased glycogen storage in the liver. Insulin resistance in adipose tissue also causes lipolysis and increased release of free fatty acids into the circulation, thus enhancing very-low-density lipoprotein (VLDL) and triglyceride synthesis in the liver. This leads to fat accumulation in the liver and decreased liver function, resulting in abnormal liver function tests. Moreover, these conditions also contribute to dyslipidemia, including high triglycerides, decreased high-density lipoprotein (HDL), and increased low-density lipoprotein (LDL) in patients with type-2 DM. Dyslipidemia increases the risk of cardiovascular disease in patents with type-2 DM [10].

Hyperglycemia also generates free radicals and contributes to vascular disease. Free radicals damage cell membranes and can lead to micro-and macrovascular complications [2]. Microvascular complications include diabetic retinopathy, diabetic nephropathy, neuropathy, and decreased liver function; macrovascular complications include atherosclerosis [11]. One mechanism behind these complications is the production of advanced glycation products (AGEs), which are products of nonenzymatic glycation of plasma proteins caused by chronic hyperglycemia. These AGEs increase oxidative stress, inflammation, and glycation of LDL and HDL, and reduce nitric oxide availability, all of which lead to the above complications [12]. This condition also provokes alteration of hemodynamics in the microcirculation of the kidney, including glomerular hyperfiltration and increased capillary pressure in the glomerulus. Glomerular hyperperfusion increases the glomerular filtration rate and causes thickening of the glomerular basement membrane. After 5 to $10 \mathrm{y}$ of these conditions, albuminuria will begin, indicating declining kidney function [2].

\section{Effect on preventing type- 2 diabetes mellitus in patients with obesity}

As stated above, obesity is often the leading cause of insulin resistance in patients with type- $2 \mathrm{DM}$. Preventing lipid accumulation might help reduce the risk of insulin resistance, thus reducing the risk of developing type-2 DM. Ethanolic extract of $G$. mangosteen showed antiobesity effects in rats with high-fat-diet-induced obesity, reducing both adipose mass and weight gain [13]. The mechanism by which the drug reduces adipose mass was clarified in an in vitro study that isolated $\alpha$-mangostin from the hulls of $G$. mangostana [14]. That study found that $\alpha$-mangostin had cytotoxic effects against 3T3-L1 cells through inhibition of fatty acid synthase. Inhibition of fatty acid synthase induces apoptosis of preadipocytes, suppresses adipocyte differentiation, and causes lipolysis of mature adipocytes, thus reducing lipid accumulation. Therefore, the authors concluded that the antiobesity effects of mangosteen might reduce the risk of insulin resistance in type-2 DM [14].

\section{Effect on blood glucose}

Glycemic control is an important goal in treating type-2 DM. Administration of mangosteen rind extract in streptozotocin (STZ)induced diabetic rats at doses of 50 and $200 \mathrm{mg} / \mathrm{kg} \mathrm{BW} /$ day for $7 \mathrm{~d}$ was shown to lower blood glucose [15]. Another study on administration of G. mangostana pericarp extract also showed a significant reduction in blood glucose levels [16] In that study, histopathology analysis of STZ-induced diabetic rats showed that the hypoglycemic effect of this extract resulted from enhancement of insulin secretion and peripheral utilization of insulin. This increase in insulin levels results from the antioxidant effects of $G$. mangostana, which causes neutralization of free radicals in the islet cells, thus initiating regeneration of insulin-producing $\beta$ cells [16]. This result was supported by another in vivo study that evaluated the effects of $\alpha$-mangostin, one of the bioactive compounds in $G$. mangostana [17]. STZ-induced diabetic rats treated with $\alpha$ mangostin showed a significant decrease in blood glucose levels at tested doses of 25, 50, and $100 \mathrm{mg} / \mathrm{kg} \mathrm{BW} /$ day. A dose of $100 \mathrm{mg} / \mathrm{kg}$ $\mathrm{BW} /$ day resulted in the maximum decrease in blood glucose, along with a significant increase in plasma insulin level. The proposed mechanism of the hypoglycemic effect exerted by $\alpha$-mangostin was protection and increased activity of pancreatic $\beta$ cells, which results in increased insulin levels, which in turn lowers blood glucose levels. This hypothesis was confirmed on histopathology, where it was found that $\alpha$-mangostin protected pancreatic $\beta$ cells from the toxic effects of STZ [17].

Evaluation of the constituents of the ethanolic extract of $G$. mangostana pericarp shows that its hypoglycemic activity might be attributable to the polyphenols present. Polyphenols such as tannins and xanthones cause hypoglycemic effects by initiating $\beta$-cell regeneration. Moreover, an in vitro study found that tannins and xanthones, especially $\gamma$-mangostin, were potent natural inhibitors of $\alpha$-amylase and $\alpha$-glucosidase, and thus reduced postprandial hyperglycemia by suppressing glucose absorption. Hence, $G$. mangostana could help lower postprandial blood glucose levels [18].

\section{Effect on inflammation}

Inflammation itself plays an important role in the development of type-2 DM and affects insulin sensitivity. CRP and TNF- $\alpha$ are markers of low-grade inflammation and vascular injury, whereas IL-6 can alter the insulin receptor, resulting in the progression of insulin resistance. Oral administration of $\alpha$-mangostin in STZ-induced diabetic rats resulted in levels of inflammatory cytokines (CRP, TNF- $\alpha$, and IL-6) decreasing to near normal in a dose-dependent manner [17]. In an 8week clinical study involving 40 patients with obesity, the group given $18 \mathrm{oz}$ of mangosteen juice per day showed a significant decrease in high-sensitivity (hs)-CRP, compared with the placebo group [19]. These studies show that mangosteen can decrease inflammatory markers such as CRP and TNF- $\alpha$.

\section{Effect on insulin secretion and insulin resistance}

In an in vitro study, $\alpha$-mangostin was shown to stimulate insulin secretion in rat pancreatic INS-1 cells by activating pancreatic and duodenal homeobox 1 and insulin receptor, followed by phosphorylation of phospho-phosphatidylinositol-3 kinase, Akt, and extracellular signal-regulated kinase-signaling cascades [20]. The compound also inhibited the phosphorylation of insulin receptor substrate. Besides enhancing insulin secretion, $\alpha$-mangostin also had a protective effect against insulin resistance in an in vivo study in STZ-induced diabetic Wistar rats [17]. Another bioactive compound of G. mangostana, $\gamma$-mangostin, was shown to prevent insulin resistance induced by lipopolysaccharide, by preventing the suppression of PPAR $\gamma$ and adiponectin gene expression [21]. One clinical trial showed that homeostatic model assessment-insulin resistance (HOMA-IR) decreased significantly more in a mangosteen-treated group than in the control group, supporting the results of previous preclinical studies [22]. Insulin resistance plays a dominant role in the pathophysiology of type-2 DM; therefore, improving insulin sensitivity can help treat DM.

\section{Effect on hepatic function}

The liver is an important organ in regulating glucose metabolism, and thus plays an important role in the pathogenesis of type-2 DM. The liver enzymes Serum Glutamic Oxaloacetic Transaminase (SGOT), Serum Glutamic Pyruvic Transaminase (SGPT), and Alkaline Phosphatase (ALP) are often used to examine the integrity of hepatocytes. Hepatocyte injury will cause these enzymes to leak into the bloodstream. A group of STZ-induced diabetic rats treated with $\alpha$-mangostin showed lower levels of SGOT, SGPT, and ALP compared with untreated STZ-induced diabetic rats [17]. A dose-dependent reduction in liver enzymes was also seen in a group of rats treated with ethanolic extract of G. mangostana pericarp, with $100 \mathrm{mg} / \mathrm{kg}$ $\mathrm{BW} /$ day producing the greatest reduction [16]. A possible mechanism of this effect is that $\alpha$-mangostin improves hepatocyte health. This effect was confirmed in a histopathology study in which reduced accumulation of fat droplets was seen in hepatocytes of STZ-induced diabetic rats treated with $\alpha$-mangostin [17].

Other enzymes, such as hexokinase, glucose-6-phosphatase, and fructose-1,6-biphosphatase are also found in the liver. Unlike SGOT, SGPT, and ALP, these enzymes are not used to evaluate hepatocyte integrity, yet they play an important role in regulating glucose metabolism in the body. Hexokinase plays a role in converting glucose to glucose-6-phosphatase so that cells can utilize glucose to produce energy. Increased hexokinase levels can reduce blood 
glucose and increase glucose utilization. Glucose-6-phosphatase and fructose-1,6-biphosphatase are enzymes that participate in converting glucose precursors to glucose. In STZ-induced diabetic rats, levels of these enzymes were found to increase whereas hexokinase decreased [17]. A significant dose-dependent increase in the level of hexokinase and decrease in the levels of glucose-6phosphatase and fructose-1,6-biphosphatase were found in STZinduced diabetic rats treated with $\alpha$-mangostin. Bringing the levels of these enzymes into the normal range helps reduce the production of hepatic glucose and lowers fat deposition in the liver; these findings were supported by histopathology [17].

Glycogen is another compound found in the liver. Insulin plays an important role in inhibiting glycogen phosphorylase and maintaining glycogen storage. The inability to maintain glycogen storage is one aspect of liver-function impairment in DM. In STZinduced diabetic rats, the level of hepatic glycogen increased with $\alpha$-mangostin treatment, indicating improved glycogen storage [17]. These results confirm the hepatoprotective effect of $G$. mangostana.

\section{Effect on lipid profile}

Reducing the risk of cardiovascular disease (CVD) is an important therapy goal for patients with type-2 DM because CVD is the leading cause of mortality in this population. Lipid profile parameters that are associated with CVD include triglycerides, LDL, VLDL, HDL, and cholesterol. In DM, triglycerides, LDL, VLDL, and cholesterol levels are increased. The fat metabolism disorder found in the diabetic condition is the cause of these elevations. STZ-induced diabetic rats treated with $\alpha$-mangostin showed significant alterations in the lipid profile, which returned to near-normal or normal conditions. It is hypothesized that $\alpha$-mangostin increases insulin levels, which results in hydrolysis of triglycerides and decreased lipolysis and fatty acid flux, thus decreasing LDL and VLDL synthesis in hepatocytes. Moreover, lower levels of LDL and VLDL in peripheral tissues enables them to excrete more HDL. These lipid-lowering effects thus decrease coronary risk. A dose-dependent decrease in the atherogenic and coronary risk index was also found in STZinduced diabetic rats treated with $\alpha$-mangostin [17].

Administering ethanolic extract of G. mangostana pericarp also lowers triglycerides, LDL, VLDL, and total cholesterol levels [16]. Because ethanol is a polar solvent, this result is in line with another study that showed that nonpolar and semipolar fractions of mangosteen pericarp extract did not reduce fasting cholesterol level in STZ-induced diabetic rats, whereas the polar extract produced a significant reduction [23]. One clinical study also showed a significant increase in HDL cholesterol in the mangosteen-treated group after $26 \mathrm{w}$, indicating a protective effect against cardiovascular risk in patients with type-2 DM [22].

\section{Effect as antioxidant}

The destructive effect of free radicals generated by hyperglycemia in type-2 DM plays an important role in micro-and macrovascular conditions. Free radicals cause lipid peroxidation and further damage cell membranes. Antioxidants are substances that inhibit the deleterious effects of free radicals, thus preventing damage to cell wall membranes, DNA, blood vessels, and other tissues. Malondialdehyde (MDA) is an end-product of lipid peroxidation and can thus be used as an indicator of cell or tissue damage caused by lipid peroxidation activity. Nonpolar, semipolar, and polar fractions of mangosteen pericarp extract have shown significant effects in decreasing serum MDA levels in rats with STZ-induced type-2 DM [23]. The group of diabetic rats treated with $\alpha$-mangostin showed restoration of endogenous antioxidant enzymes to near-normal levels. Hepatic and renal superoxide dismutase and catalase, which are first-line endogenous scavenging enzymes, increased, confirming the antioxidant effect of $\alpha$-mangostin, which acts as a free radicalscavenging compound [17]. Xanthones from mangosteen provide additional antioxidants to counter the destructive effects of free radicals. In a study of xanthone administration, a phenolic compound isolated from the pericarp of G. mangostana reduced plasma and renal MDA levels, indicating the antioxidant effects of this compound [24].

In hyperglycemia, the process of glycation occurs. This has been used as a marker of oxidative stress in this condition. STZ-induced diabetic rats treated with $\alpha$-mangostin showed decreased levels of glycated hemoglobin, indicating reduced oxidative stress. It is possible that this action of $\alpha$-mangostin results from enhancement of endogenous antioxidant levels and reduced blood glucose. It is accepted that enhanced antioxidant activity prevents diabetic complications.

\section{Effect on renal function}

Reactive oxygen species generated in hyperglycemia cause lipid peroxidation and can injure the kidney, resulting in diabetic nephropathy. Renal dysfunction in STZ-induced diabetic rats is marked by increased levels of creatinine and blood urea nitrogen (BUN), with decreased levels of total protein. STZ-induced diabetic rats treated with $\alpha$-mangostin showed decreased levels of serum creatinine and BUN, and increased total protein levels [17]. Rats treated with $\alpha$-mangostin at $100 \mathrm{mg} / \mathrm{kg}$ BW/day showed more improvement in renal parameters than rats receiving different treatment doses. It has been hypothesized that $\alpha$-mangostin decreases the protein degradation that occurs in DM. This hypothesis is supported by histopathology findings that show significant decreases in glomerular focal necrosis and tubular epithelial necrosis in $\alpha$-mangostin-treated rats [17]. Significant improvement in renal markers was also seen after treatment with ethanolic extract and xanthone of $G$. mangostana pericarp as a result of scavenging of the free radicals generated in hyperglycemia [16, 25] This extract improved renal parameters, supporting the above results on the ability of $G$. mangostana to ameliorate renal dysfunction in type-2 DM. It was thus concluded that $G$. mangostana might have renoprotective effects [17].

\section{Effect on advanced glycation end-products (AGEs) and other DM complications}

AGEs result from nonenzymatic reactions between the amino group of a protein and the carbonyl group of a sugar during hyperglycemia. AGEs are used clinically as an indicator of short-term blood glucose control in diabetic patients. The accumulation and precipitation of AGEs in body tissues leads to several complications of chronic diabetes, including atherosclerosis, retinopathy, neuropathy, nephropathy, endothelial dysfunction, and Alzheimer's disease [25, 26]. Six known compounds and two new xanthones of $G$. mangostana, mangostanaxanthones III and IV, were isolated from methanol extract of $G$. mangostana pericarp. These isolated metabolites inhibited both sugar-and dicarbonyl compound-induced protein glycation. Hence, these metabolites were confirmed to have anti-AGE properties [25]. Moreover, four phenolic compounds isolated from methanol extract of $G$. mangostana pericarp inhibited AGE formation at the levels of Amadori product and protein aggregation by saving protein thiols [26].

Aldose reductase is an enzyme that plays a role in the polyol pathway by catalyzing the reduction of glucose to sorbitol with oxidation of NADPH to NADP+. Increased sorbitol is thought to play a role in diabetic complications, such as cardiovascular autonomic neuropathy. A study that used dichloromethane extract of the root bark of G. mangostana Linn demonstrated that its xanthones were potent human aldose reductase inhibitors. The most potent xanthone against aldose reductase was 3-isomangostin. These findings validated mangosteen as a potent aldose reductase inhibitor, indicating that it can reduce the risk of diabetic complications [27].

\section{Summary of the effects of $G$. mangostana in type-2 diabetes mellitus}

One study compared different forms of G. mangostana and found that G. mangostana extract had higher bioavailability than the isolated pure conjugated xanthone, $\alpha$-mangostin [28] A summary of the effects of $G$. mangostana in type-2 DM is shown in table 1. 
Table 1: Summary of the effects of Garcinia mangostana in type-2 diabetes mellitus

\begin{tabular}{|c|c|c|c|}
\hline Study design & Garcinia mangostana component/dose & Results & Reference \\
\hline $\begin{array}{l}\text { In vitro: human } \\
\text { adipocytes }\end{array}$ & $\gamma$-mangostin & $\begin{array}{l}\text { Prevented LPS-mediated insulin } \\
\text { resistance in human adipocytes }\end{array}$ & $\begin{array}{l}\text { Bumrungpert et } \\
\text { al., } 2009\end{array}$ \\
\hline In vitro & Ethanol extract of fruit hull & $\begin{array}{l}\text { Inhibited } \alpha \text {-glucosidase } \\
\downarrow \text { postprandial blood glucose level }\end{array}$ & Ryu et al., 2011 \\
\hline In vitro: 3T3-L1 cells & $\alpha$-mangostin from hulls & $\begin{array}{l}\text { Inhibited fatty acid synthase } \\
\uparrow \text { lipolysis }\end{array}$ & $\begin{array}{l}\text { Quan et al., } \\
2012\end{array}$ \\
\hline In vitro & $\begin{array}{l}\text { Dichloromethane extract of root bark ( } \alpha \text {-mangostin, } \beta \text { - } \\
\text { mangostin, } 3 \text {-isomangostin) }\end{array}$ & Inhibited aldose reductase & $\begin{array}{l}\text { Fatmawati et } \\
\text { al., } 2014\end{array}$ \\
\hline In vitro & $\begin{array}{l}\text { Pericarp methanol extract containing } \\
\text { mangostanaxanthones III and IV }\end{array}$ & $\downarrow$ advanced glycation end-product & $\begin{array}{l}\text { Abdallah et al., } \\
2017\end{array}$ \\
\hline In vitro & Phenolic compounds isolated from fruit hulls & $\downarrow$ advanced glycation end-product & $\begin{array}{l}\text { Abdallah et al., } \\
2016\end{array}$ \\
\hline $\begin{array}{l}\text { In vitro: rat pancreatic } \\
\text { INS-1 cells }\end{array}$ & $\alpha$-Mangostin & $\uparrow$ insulin secretion & Lee et al., 2018 \\
\hline $\begin{array}{l}\text { In vivo: STZ-induced } \\
\text { male rats }\end{array}$ & $\begin{array}{l}\alpha \text {-Mangostin; given at } 25,50 \text {, or } 100 \mathrm{mg} / \mathrm{kg} / \text { day orally } \\
\text { for } 56 \mathrm{~d}\end{array}$ & $\begin{array}{l}\downarrow \text { blood glucose level; } \\
\uparrow \text { plasma insulin level; } \\
\downarrow \text { HOMA IR; } \\
\uparrow \text { hexokinase; } \downarrow \text { G-6-Pase; } \downarrow \text { fructose-1,6- } \\
\text { biphosphatase; } \downarrow \text { SGOT, SGPT, and ALP; } \\
\downarrow \text { LDL and VLDL; } \uparrow \text { HDL; reduced } \\
\text { atherogenic and coronary risk index; } \\
\uparrow \text { antioxidant enzymes (SOD and CAT); } \\
\downarrow \text { glycated hemoglobin (lowering } \\
\text { oxidative stress); } \\
\uparrow \text { liver glycogen storage; } \\
\downarrow \text { serum creatinine and BUN, } \uparrow \text { total } \\
\text { protein; } \\
\downarrow \text { inflammatory cytokines (CRP, TNF- } \alpha \text {, } \\
\text { and IL-6) }\end{array}$ & $\begin{array}{l}\text { Kumar et al., } \\
2016\end{array}$ \\
\hline $\begin{array}{l}\text { In vivo: high fat diet- } \\
\text { induced for } 3 \mathrm{w} \text { prior to } \\
\text { STZ-induction male } \\
\text { mice }\end{array}$ & $\begin{array}{l}\text { Pericarp extract of } G \text {. mangostana, macerated with three } \\
\text { solvents: n-hexane (nonpolar fraction), chloroform } \\
\text { (semipolar fraction), ethanol (polar fraction); given } \\
\text { orally to three groups of mice for } 14 \mathrm{~d} \text {, dose } \sim 100 \mathrm{mg} / \mathrm{kg} \\
\text { BW of crude extract }\end{array}$ & $\begin{array}{l}\downarrow \text { fasting blood cholesterol in polar } \\
\text { fraction } \\
\downarrow \text { MDA levels }\end{array}$ & $\begin{array}{l}\text { Husen et al., } \\
2016\end{array}$ \\
\hline $\begin{array}{l}\text { In vivo: high-fat diet } \\
\text { male mice }\end{array}$ & $\begin{array}{l}\text { Ethanolic peel extract of } G \text {. mangostana; } 50 \text { or } 200 \mathrm{mg} / \mathrm{kg} \\
\text { containing } 25.7 \% \alpha \text {-mangostin and } 3.8 \% \gamma \text {-mangostin }\end{array}$ & $\begin{array}{l}\downarrow \text { adipose mass } \\
\downarrow \text { TG, LDL, TC } \\
\downarrow \text { blood glucose level }\end{array}$ & $\begin{array}{l}\text { Chae et al., } \\
2016\end{array}$ \\
\hline $\begin{array}{l}\text { In vivo: STZ-induced } \\
\text { white male rats }\end{array}$ & Mangosteen rind extract for $7 \mathrm{~d}$ & $\downarrow$ blood glucose level & $\begin{array}{l}\text { As'ari et al., } \\
2016\end{array}$ \\
\hline $\begin{array}{l}\text { In vivo: STZ-induced } \\
\text { male rats }\end{array}$ & $\begin{array}{l}\text { Ethanolic extraction (by maceration) powder of } G \text {. } \\
\text { mangostana pericarp; } 50,100 \text {, or } 200 \mathrm{mg} / \mathrm{kg} \text { BW } \\
\text { administered orally as (1) single dose or (2) multiple } \\
\text { doses for } 14 \mathrm{~d}\end{array}$ & $\begin{array}{l}\downarrow \text { blood glucose level } \\
\downarrow \text { TG, LDL, VLDL, TC } \\
\downarrow \text { SGOT, SGPT } \\
\downarrow \text { serum creatinine, BUN, total protein }\end{array}$ & $\begin{array}{l}\text { Taher et al., } \\
2016\end{array}$ \\
\hline $\begin{array}{l}\text { In vivo: high fat diet- } \\
\text { induced for } 3 \mathrm{w} \text { prior to } \\
\text { STZ-induced male mice }\end{array}$ & Xanthone at doses of 100,200 , or $400 \mathrm{mg} / \mathrm{kg} \mathrm{BW}$ & $\begin{array}{l}\downarrow \text { plasma MDA, kidney MDA } \\
\downarrow \text { serum creatinine, BUN, kidney } \\
\text { hypertrophy }\end{array}$ & $\begin{array}{l}\text { Karim et al., } \\
2017\end{array}$ \\
\hline RCT & $\begin{array}{l}400 \mathrm{mg} \text { mangosteen fruit pulp extract titrated to } 40 \% \text { in } \\
\alpha \text {-and } \gamma \text {-mangostin }(160 \mathrm{mg} \text { ) per day for } 26 \mathrm{w}\end{array}$ & $\begin{array}{l}\uparrow \text { insulin sensitivity: HOMA-IR } \\
\text { decreased by } 51.3 \% \\
\uparrow \text { HDL }\end{array}$ & $\begin{array}{l}\text { Watanabe et al., } \\
2018\end{array}$ \\
\hline RCT & $8 \mathrm{w}$ of $18 \mathrm{oz}$ mangosteen juice per day & $\downarrow$ hs-CRP & $\begin{array}{l}\text { Udani et al., } \\
2009\end{array}$ \\
\hline
\end{tabular}

\section{CONCLUSION}

This review showed the potential pharmacological benefits of $G$. mangostana extracts and isolates in preventing and treating type- 2 DM. However, human studies using long-term biomarkers are lacking. To confirm the promising preventive and therapeutic effects of G. mangostana in type-2 DM, a clinical trial using long-term biomarkers is needed to evaluate the glycemic control effect, which is one important goal of therapy in DM.

\section{ACKNOWLEDGMENT}

All authors were involved in the planning of this review. P. A. M. Subroto performed study selection and data extraction. R. P. Priawan screened the articles. J. E. Hanrahan wrote the first draft of the manuscript. All authors contributed to further drafts and authorized the final manuscript. This article was presented at The $3^{\text {rd }}$ International Conference and Exhibition on Indonesian Medical Education and Research Institute (ICE on IMERI 2018),
Faculty of Medicine, Universitas Indonesia, Jakarta, Indonesia. We thank the $3^{\text {rd }}$ ICE on IMERI Committee who had supported the peer review and manuscript preparation before submitting to the journal.

\section{AUTHORS CONTRIBUTIONS}

All the author have contributed equally

\section{CONFLICT OF INTERESTS}

\section{Declared none}

\section{REFERENCES}

1. Mathers CD, Loncar D. Projections of global mortality and burden of disease from 2002 to 2030. Plos Med 2006;3:442.

2. Kasper DL, Hauser SL, Jameson JL, Fauci AS, Longo DL, Loscalzo J. Harrison's principles of internal medicine. 19th ed. New York: McGraw Hill; 2015. p. 2399-406. 
3. Nathan DM, Buse JB, Davidson MB, Ferrannini E, Holman RR Sherwin R, et al. Medical management of hyperglycaemia in type 2 diabetes mellitus: a consensus algorithm for the initiation and adjustment of therapy: a consensus statement from the American diabetes association and the European association for the study of diabetes. Diabetologia 2009;52:17-30.

4. Chaudhury A, Duvoor C, Reddy Dendi VS, Kraleti S, Chada A, Ravilla $\mathrm{R}$, et al. Clinical review of antidiabetic drugs: implications for type 2 diabetes mellitus management. Front Endocrinol 2017;8:1-7.

5. Wang Z, Wang J, Chan P. Treating type 2 diabetes mellitus with traditional Chinese and Indian medicinal herbs. Evid Based Complement Alternat Med 2013;1-17. http://dx.doi.org/10.1155/2013/343594

6. Chang CLT, Lin Y, Bartolome AP, Chen YC, Chiu SC, Yang WC. Herbal therapies for type 2 diabetes mellitus: chemistry, biology, and potential application of selected plants and compounds. Evid Based Complement Alternat Med 2013;1-33. Doi:10.1155/2013/378657

7. Yang R, Li P, Li N, Zhang Q, Bai X, Wang L, et al. Xanthones from the pericarp of Garcinia mangostana. Molecules 2017;22:683.

8. Ragasa C, Tabin T, Reyes J, Tan M, Shen C. Chemical constituents of Garcinia mangostana pulp and seeds. Int J Pharm Clin Res 2016;8:1166-9.

9. Gutierrez Orozco F, Failla M. Biological activities and bioavailability of mangosteen xanthones: a critical review of the current evidence. Nutrients 2013;5:3163-83.

10. Mohamed J, Nafizah N, Zariyantey AH, Budin SB. Mechanisms of diabetes-induced liver damage: the role of oxidative stress and inflammation. Sultan Qaboos Univ Med J 2016;16:132-41.

11. Chawla A, Chawla R, Jaggi S. Microvascular and macrovascular complications in diabetes mellitus: distinct or continuum? Indian J Endocrinol Metab 2016;20:546-51.

12. Stirban A, Gawlowski T, Roden M. Vascular effects of advanced glycation endproducts: clinical effects and molecular mechanisms. Mol Metab 2013;3:94-108.

13. Chae HS, Kim YM, Bae JK, Sorchhann S, Yim S, Han L, et al. Mangosteen extract attenuates the metabolic disorders of highfat-fed mice by activating AMPK. J Med Food 2016;19:148-54.

14. Quan X, Wang Y, Ma X, Liang Y, Tian W, Ma Q, et al. $\alpha$-Mangostin induces apoptosis and suppresses differentiation of 3T3-L1 cells via inhibiting fatty acid synthase. PLoS One 2012;7:e33376.

15. Asari H, Mahartini D. The effect of administering mangosteen rind extract (Garcinia mangostana L) compared with glimepride to the blood sugar levels of white male rate (Rattus norwegicus l) induced by streptozotocin. Folia Medica Indones 2016;52:241-5.

16. Taher M, Tg Zakaria TMFS, Susanti D, Zakaria ZA Hypoglycaemic activity of ethanolic extract of Garcinia mangostana Linn. in normoglycaemic and streptozotocin- induced diabetic rats. BMC Complement Altern Med 2016;16:135.

17. Kumar V, Bhatt PC, Kaithwas G, Rashid M, Al-abbasi FA, Khan JAJ, et al. $\alpha$-Mangostin mediated pharmacological modulation of hepatic carbohydrate metabolism in diabetes induced Wistar rat. Beni Suef Univ J Basic Appl Sci 2016;5:255-76.

18. Ryu HW, Cho JK, Curtis Long MJ, Yuk HJ, Kim YS, Jung S, et al. $\alpha$ glucosidase inhibition and antihyperglycemic activity of prenylated xanthones from garcinia mangostana. Phytochemistry 2011;72:2148-54

19. Udani JK, Singh BB, Barrett ML, Singh VJ. Evaluation of mangosteen juice blend on biomarkers of inflammation in obese subjects: a pilot, dose finding study. Nutr J 2009;8:1-7.

20. Lee D, Kim YM, Jung K, Chin YW, Kang K. Alpha-mangostin improves insulin secretion and protects INS-1 cells from streptozotocin-induced damage. Int J Mol Sci 2018;19:1484.

21. Bumrungpert A, Kalpravidh RW, Chitchumroonchokchai C, Chuang CC, West T, Kennedy A, et al. Xanthones from mangosteen prevent lipopolysaccharide-mediated inflammation and insulin resistance in primary cultures of human adipocytes. J Nutr 2009;139:1185-91.

22. Watanabe M, Gangitano E, Francomano D, Addessi E, Toscano $\mathrm{R}$, Costantini D, et al. Mangosteen extract shows a potent insulin sensitizing effect in obese female patients: a prospective randomized controlled pilot study. Nutrients 2018;10:586.

23. Husen SA, Winarni D, Khaleyla F, Kalqutny SH. Activity test of various mangosteen (Garcinia mangostana) pericarp extract fractions to decrease fasting blood cholesterol levels and lipid peroxidation activity in diabetic mice. J Biol Res 2016;22:13-7.

24. Karim N, Jeenduang N, Tangpong J. Renoprotective effects of xanthone derivatives from garcinia mangostana against high fat diet and streptozotocin-induced type II diabetes in mice. Walailak J Sci Technol 2018;15:107-16.

25. Abdallah HM, El-Bassossy HM, Mohamed GA, El-Halawany AM, Alshali KZ, Banjar ZM. Mangostanaxanthones III and IV: advanced glycation end-product inhibitors from the pericarp of Garcinia mangostana. J Nat Med 2017;71:216-26.

26. Abdallah H, El-Bassossy H, Mohamed G, El-Halawany A, Alshali $\mathrm{K}$, Banjar Z. Phenolics from garcinia mangostana inhibit advanced glycation endproducts formation: effect on Amadori products, cross-linked structures and protein thiols. Molecules 2016;21:251.

27. Fatmawati S, Ersam T, Shimizu K. The inhibitory activity of aldose reductase in vitro by constituents of garcinia mangostana Linn. Phytomedicine 2014;22:49-51.

28. Li L, Han AR, Kinghorn A, Frye R, Derendorf H, Butterweck V. Pharmacokinetic properties of pure xanthones in comparison to a mangosteen fruit extract in rats. Planta Med 2013;79:64653. 